\title{
The Impact of Daily Behavior Patterns on the Thermal Comfort of Human Bodies in Rural Heating Houses of Northern China
}

\author{
Xueyan Zhang*, Bin Chen \\ Laboratory of Building Environment and New Energy Resources, Dalian University of Technology, \\ Dalian, Liaoning 116024, China \\ *zxychenggong2008@126.com
}

\begin{abstract}
Keywords: Kang; Burning cave; Radiators driven by mini-stove; Human activities; Exergy efficiency Abstract. Nowadays, traditional heating systems represented by kang still impact people's daily life profoundly in rural areas of northern China. While residents in the case of different activities in rooms respectively heated by different heating methods, the heat transfer quantity and exergy efficiency of each heating system have been calculated and the more comfortable posture for a person has been confirmed. Based on theoretical calculations, the variation coefficient of indoor air temperature in a room heated by kang and burning cave is only 0.28 , which was the smallest among all the conditions, suggesting that its indoor thermal stability is best as well as its indoor thermal comfort, and the heat a human body obtains is the highest by the position of laying supine on the kang plate, $24.32 \mathrm{~W}$. However, the lowest radiant heat of a human body is $4.36 \mathrm{~W}$ while the man stands on the ground in a room heated only by kang. Through comparison, exergy efficiency of the burning cave integrated with kang is $55 \%$, with a largest application potential.
\end{abstract}

\section{Introduction}

In recent years, Chinese academia and general public spark a debate and discussion over the necessity of keeping the traditional heating approaches due to its low thermal efficiency, poor indoor air quality, harmful to human health and rapid urbanization. People advocating for the traditional heating approaches present the following evidence: (1) the households of traditional heating houses are approximately 166 million in northern China [1]; (2) the energy crisis and serious environmental pollution could be aggravated by the use of central heating system in widely dispersed houses in rural areas; (3) a lot of biomass resources could not be efficiently used and crop wastes are disposed only by open burning on the farmland, which would cause serious air pollution and traffic accidents. Thus, to increase thermal efficiency of traditional heating systems and improving indoor living environment has already become an important research subject. A large number of field surveys, experimental and theoretical researches on the forms and constructions, and integrated application modes of traditional heating systems like kangs and burning caves have been conducted [2-4].

\section{Measured houses and conditions}

Residents' daily living comfort is closely related to the application modes of traditional heating methods and human daily activities. From 2012 to 2013 winter, there were three different houses for measurements in Fuxin rural area, including one house heated only by kang, one house heated by kang and radiators, and one house heated by kang and burning cave. Measured houses and test points arrangements are all shown in Fig. 1. The thermal performances of these three measured houses are similar. The indoor/outdoor air temperature and relative humidity have been measured by thermo recorder TR-72U. All the measurements were recorded every 10 minutes and stored in a computer. Test period was from December 10, 2012 to January 15, 2013. 


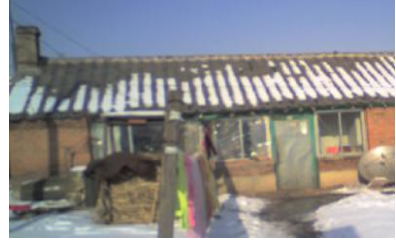

Dwelling

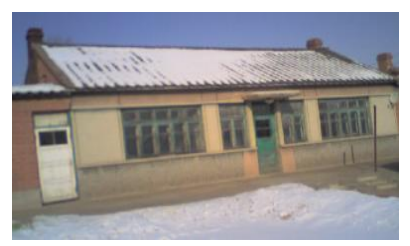

Dwelling

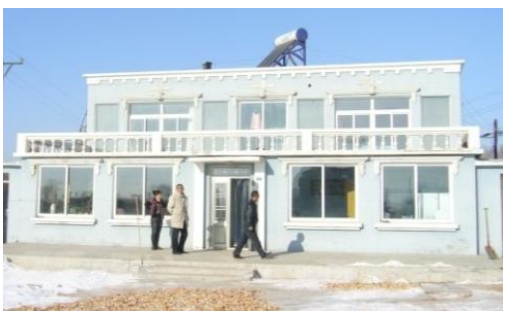

Dwelling

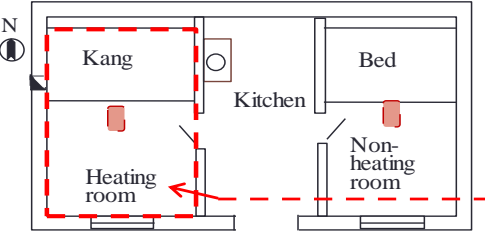

Building Plan

(a)

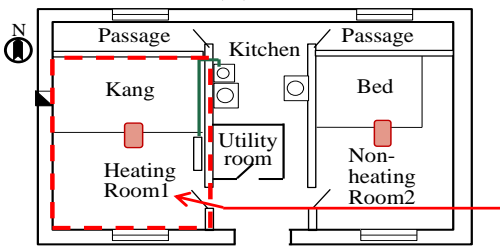

Building Plan

(b)

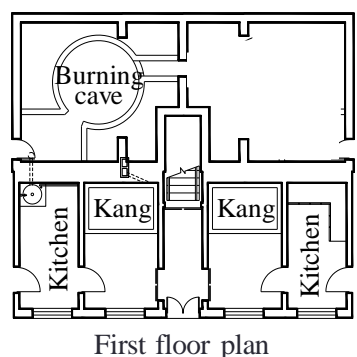

(c)

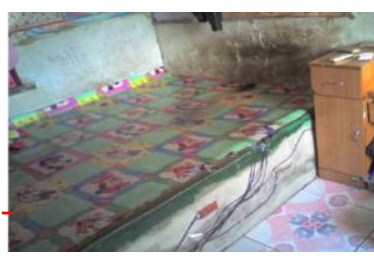

Kang heating room

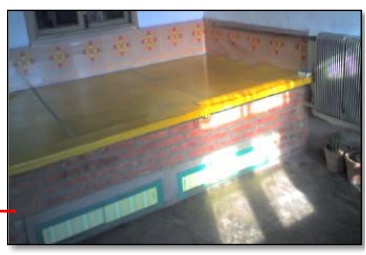

Kang and radiator

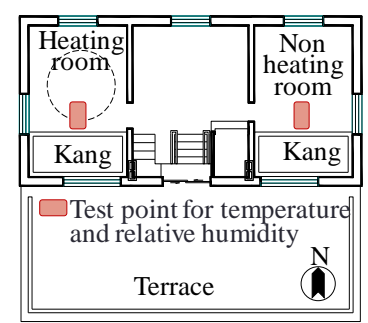

Second floor plan

Fig. 1 Measured house and test points ((a) Measured house heated by kang; (b) Measured house heated by kang and radiators; (c) Measured house heated by kang and burning cave.)

\section{Comparison of indoor thermal and relative humidity environment}

The statistical graph of indoor thermal and relative humidity environment in a heating house with different heating methods and variation coefficients of indoor air temperature are shown in Fig. 2 . The average temperatures of a room respectively heated by kang, kang and radiator, kang and burning cave are $10^{\circ} \mathrm{C}, 17.5^{\circ} \mathrm{C}$ and $10.5^{\circ} \mathrm{C}$. It is verified that the temperature fluctuation in the room heated by combined heating method of burning cave and kang is the smallest, which could accord with the adaptive comfort zone indicated in ASHRAE handbook. The variation coefficients of indoor air temperature in a room heated by burning cave and kang is the lowest to 0.28 , the indoor thermal stability is better. 


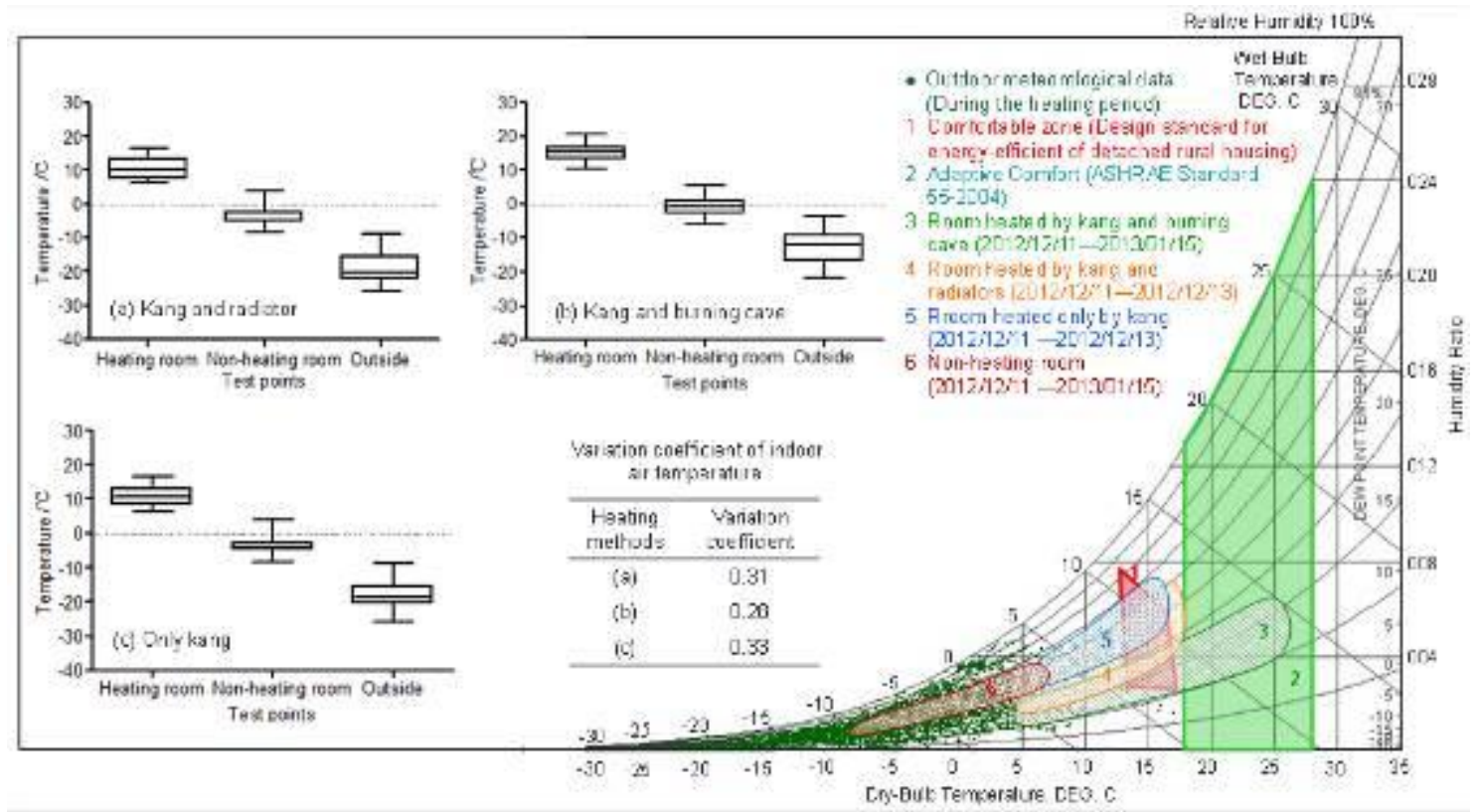

Fig. 2 Comparison indoor thermal with humidity environment under different heating methods

\section{Heat exchange of human body under different activities}

According to a number of measurements during the heating period from 2010 to 2014, the average temperatures of surfaces inside the building envelopes and the average indoor air temperatures of the three heating rooms mentioned above have been listed in Table 1. Based on these results, the heat gain and the comfort of a human body under different living activities have been researched.

Table 1 Average temperatures of the building envelopes and average indoor air temperatures $\left({ }^{\circ} \mathrm{C}\right)$

\begin{tabular}{|c|c|c|c|c|c|c|c|c|c|}
\hline $\begin{array}{c}\text { Heating } \\
\mathrm{T}\left({ }^{\circ} \mathrm{C}\right. \\
\text { Heathods }\end{array}$ & $T_{\text {in,air }}$ & $\begin{array}{l}\text { Ceilin } \\
\mathrm{g}\end{array}$ & $\begin{array}{l}\text { Floo } \\
\mathrm{r}\end{array}$ & $\begin{array}{l}\text { Easter } \\
\mathrm{n} \text { wall }\end{array}$ & $\begin{array}{l}\text { Souther } \\
\mathrm{n} \text { wall }\end{array}$ & $\begin{array}{l}\text { Wester } \\
\mathrm{n} \text { wall }\end{array}$ & $\begin{array}{l}\text { Norther } \\
\mathrm{n} \text { wall }\end{array}$ & $\begin{array}{l}\text { Kan } \\
\text { g } \\
\text { plat } \\
\text { e }\end{array}$ & $\begin{array}{l}\text { Walls } \\
\text { aroun } \\
\text { d kang }\end{array}$ \\
\hline Kang & 11.2 & 9.0 & 5.0 & 12.4 & 14.8 & 11.0 & 10.0 & 30.0 & 10.0 \\
\hline $\begin{array}{l}\text { Kang and } \\
\text { radiators }\end{array}$ & 12.0 & 10.0 & 5.0 & 15.0 & 13.2 & 14.0 & 12.6 & 31.6 & 15.0 \\
\hline $\begin{array}{l}\text { Kang and } \\
\text { burning cave }\end{array}$ & 16.2 & 12.0 & 32.0 & 17.2 & 18.4 & 15.0 & 14.0 & 33.2 & 14.0 \\
\hline
\end{tabular}

The heat distribution of the heating room is often uneven, generated by using different heating systems and different heat transfer approaches. There are five positions between a human body and the heating facilities, as shown in Fig. 3. It is necessary to analyze the heat gain and heat loss for a human body, including the following aspects: (1) Residents can receive much conductive heat through the direct contact area between human body and heating facility. (2) At the same time, residents can also gain much cold radiative heat from the lower temperature surface inside the building envelopes. (3) The convective heat transfer occurs between human body surface and indoor air. 


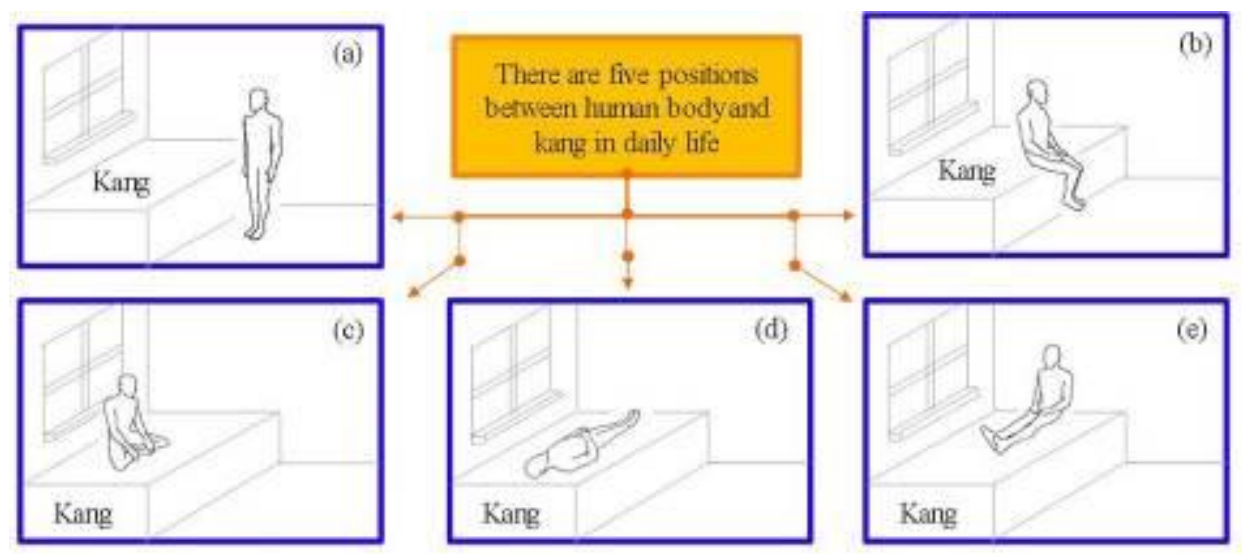

Fig. 3 Postures between people and heating system in the daytime ((a) Standing on the ground; (b) Sitting on the edge of a kang; (c) Cross-legged sitting on a kang; (d) Laying supine on a kang; (e) leg-out sitting on a kang.

The radiant and convective heat transfer coefficient of a human body has been from reference[5]. The radiation heat exchange angle coefficient between the human body surface and the surfaces inside building envelopes of each room. The human behaviors are changing in daily time. While standing, the formula for calculating the average radiant temperature of a person [5] is:

$$
t_{r s \tan d}=0.06\left(t_{\text {up }}+t_{\text {down }}\right)+0.22\left(t_{\text {left }}+t_{\text {right }}+t_{\text {frount }}+t_{\text {back }}\right)
$$

While sitting on a kang, the average radiant temperature of a person could be calculated by Eq. 2:

$$
t_{\text {rsit }}=0.127\left(t_{\text {up }}+t_{\text {down }}\right)+0.186\left(t_{\text {left }}+t_{\text {right }}+t_{\text {frount }}+t_{\text {back }}\right)
$$

Where, $t_{\text {rstand }}$ is the average radiant temperature while standing, ${ }^{0} \mathrm{C} ; t_{\text {rsit }}$ is the average radiant temperature while sitting, ${ }^{0} \mathrm{C}$; $t_{\text {up }}$ is the average surface temperature inside the ceiling, ${ }^{0} \mathrm{C}$; $t_{\text {down }}$ is average surface temperature on the floor, ${ }^{0} \mathrm{C} ; t_{\text {left }}$ is the average surface temperature inside the wall on the left of a human body, ${ }^{0} \mathrm{C}$; $t_{\text {right }}$ is the average surface temperature inside the wall on the right of a human body, ${ }^{0} \mathrm{C}$; $t_{\text {frount }}$ is the average surface temperature inside the wall in the front of a human body, ${ }^{0} \mathrm{C} ; t_{\text {back }}$ is the average surface temperature inside the wall behind a human body, ${ }^{0} \mathrm{C}$. The dimensionless correction coefficient of the surface areas of a body under different postures, chosen from reference [6]. $a_{\mathrm{ct}}$ is the area coefficient of winter dress, with the value is 1.55 [7].

As can be seen in Fig. 4, room heated by burning cave and kang, the radiant heat gain is the highest to $24.32 \mathrm{~W}$, while people laying supine on a kang. However, the direct heat transfer area between a human body and kang plate is $0.75 \mathrm{~m}^{2}$, and the heat effect of conduction and radiation is obvious. Besides, the thermal comfort in a room heated only by intermittent heating kang is the worst. However, residents could feel warmer and more comfortable in case of Fig. 4(c), (d) and (e).

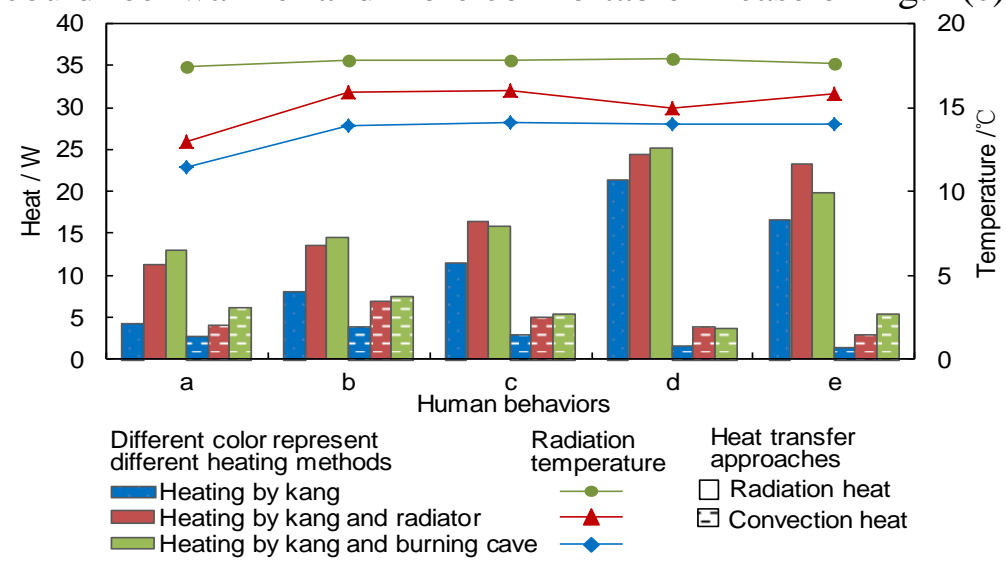

Fig. 4 The heat transfer between human body and different heating systems. ((a) standing on the ground, (b) sitting on the edge of a kang, (c) cross-legged sitting on a kang; (d) laying supine on a kang, (e) leg-out sitting on a kang.) 


\section{Conclusions}

In this paper, the main conclusions are as follows:

(1) Through field measurements and comparison, the variation coefficient of indoor air temperature in a room heated by burning cave and kang is the lowest, and the result is 0.28 , indicating a better indoor thermal stability.

(2) According to the analysis results of the application effects of traditional heating methods in ordinary living, the most comfortable positions are cross-legged sitting on the kang plate, laying supine on the kang plate and leg-out sitting on the kang plate.

\section{Acknowledgements}

The work was supported by a NSFC (No.51178073) and a postdoctoral science foundation (No.2015M571306) of China.

\section{References}

[1] Building Energy Research Center of Tsinghua University. 2014 Annual report on China building energy efficiency. China Architecture and Building press, (2014) 4-5 (in Chinese).

[2] B. Robert, W.O. Bjarne, K.W. Kim. History of Radiant Heating \& Cooling System: part I. ASHRAE Journal, January 2010.

[3] X.Y. Zhang, B. Chen, Joe R. Zhao, X. Li, S. Liu, L.H. Wu. Energy and Buildings, 68(2014) 423-431.

[4] Z. Zhuang, Y.G. Li, B. Chen. Energy and Buildings. 41(4)(2009) 452-459.

[5] C.T. Che, S.Biao, C.Z. Fu. The radiant and convective heat transfer coefficient of a human body. Japanese architectural society paper sets. 258-8 (1977) (in Chinese).

[6] F.F. Al-ajmi, D.L. Loveday, K.H. Bedwell, et al. Applied Ergonomics, 3(39) (2008) 407-414.

[7] Y. Kurazumi, T. Tsuchikawa, N. Matsubara, etc.. Building and Environment, 10(43) (2008) 1555-1565. 